\title{
Gadolinium polytungstate nanoclusters: a new theranostic with ultrasmall size and versatile properties for dual-modal MR/CT imaging and photothermal therapy/radiotherapy of cancer
}

\author{
Yuan Yong ${ }^{1,3}$, Liangjun Zhou ${ }^{1,3}$, Shuangshuang Zhang ${ }^{2}$, Liang Yan ${ }^{1}$, Zhanjun $\mathrm{Gu}^{1}$, Guangjin Zhang ${ }^{2}$ and \\ Yuliang Zhao ${ }^{1}$
}

The development of a new generation of nanoscaled theranostics with simple compositions and versatile properties to realize enhanced diagnoses and treatment outcomes and to avoid side effects is highly desirable but remains a great challenge. Here we report a new ultrasmall theranostic based on bovine serum albumin-coated $\mathrm{GdW}_{10} \mathrm{O}_{36}$ nanoclusters ( $\mathrm{GdW}_{10} \mathrm{NCs}$ ) as multifunctional theranostics for multifunctional bio-imaging, highly effective in vitro photothermal ablation of cancer cells and in vivo radiotherapy of tumors. The as-synthesized $\mathrm{GdW}_{10} \mathrm{NCs}$ afford significantly enhanced computed tomography/magnetic resonance imaging signals and remarkable photothermal therapy (PTT)/radiotherapy therapy (RT) therapeutic effects for tumor treatment. Moreover, toxicity studies confirmed their low toxicity and efficient renal clearance, suggesting their potential for practical applications. These results indicated that the as-prepared $\mathrm{GdW}_{10}$ nanoclusters are promising as multifunctional nanotheranostics for multimodal imaging-guided PTT/RT of tumors. These results also encourage the further exploration of other polyoxometalate-based multifunctional nanotheranostics for cancer diagnoses and therapy.

NPG Asia Materials (2016) 8, e273; doi:10.1038/am.2016.63; published online 27 May 2016

\section{INTRODUCTION}

New nanomaterials (NMs) for the diagnosis and treatment of cancer have recently received significant attention and have become an important field in biomedical research. ${ }^{1-10}$ One major advantage of $\mathrm{NMs}$ is their capability to integrate multiple imaging/treatment modalities into one particle, thereby developing a new generation of theranostics. ${ }^{11-16}$ The synergistic combination of bio-imaging and localized treatment capabilities is unique for nano-sized objects and may offer unprecedented opportunities to achieve better anti-cancer efficacies at tumor sites while mitigating undesired side effects. ${ }^{17-23}$ Over the past decade, theranostics based on NMs have been extensively explored. Studies have mainly focused on the construction or optimization of hybrid nanocomposites that integrate multiple imaging approaches and therapeutic modalities to realize concurrent diagnostic and therapeutic capabilities. ${ }^{24-29}$ However, the integration of two or more different components into one nanoparticle is difficult and typically requires complicated synthetic processes, thus greatly limiting their practical applications. Moreover, most of the previously reported multifunctional nanoprobes have relatively large hydrodynamic diameters (typically $>10 \mathrm{~nm}$ ), which are larger than the kidney filtration thresholds (that is, $5.5 \mathrm{~nm}$ ). ${ }^{30,31}$ Consequently, these nanoparticles cannot be metabolized by the kidney and are instead absorbed by the reticuloendothelial system in the liver and spleen, causing potential organ and immune system damage. Therefore, there is a great demand to develop small-sized nanoscale theranostics that have simple compositions with versatile properties to realize enhanced diagnostic and treatment capabilities and to avoid side effects in vivo.

Polyoxometalates (POMs) are potential candidates for ultrasmall nanotheranostics due to their unique molecular structure, good water solubility and small particle size. ${ }^{32-35}$ As a class of important inorganic nanoclusters, POMs are composed of transition metals and/or rare earth elements bridged by oxo ligands. Many heteroatoms can be incorporated into a POM framework, including Gd, Mn

${ }^{1}$ CAS Key Laboratory for Biomedical Effects of Nanomaterials and Nanosafety, Institute of High Energy Physics and National Center for Nanoscience and Technology of China, Chinese Academy of Sciences, Beijing, People's Republic of China and ${ }^{2}$ Key Laboratory of Green Process and Engineering, Institute of Process Engineering, Chinese Academy of Sciences, Beijing, People's Republic of China

${ }^{3}$ These authors contributed equally to this work.

Correspondence: Professor Z Gu or Professor Y Zhao, CAS Key Laboratory for Biomedical Effects of Nanomaterials and Nanosafety, Institute of High Energy Physics and National Center for Nanoscience and Technology of China, Chinese Academy of Sciences, Yuquan Road 19b Shijingshan District, 100049 Beijing, People's Republic of China.

E-mail: zjgu@ihep.ac.cn or zhaoyuliang@ihep.ac.cn

or Professor G Zhang, Key Laboratory of Green Process and Engineering, Institute of Process Engineering, Chinese Academy of Sciences, Zhongguancun South Road No. 12 Haidian District, 100190 Beijing, People's Republic of China.

E-mail: zhanggj@ipe.ac.cn

Received 16 November 2015; revised 28 January 2016; accepted 15 March 2016 
and $\mathrm{Cu}$, to impart various properties. ${ }^{36-39}$ These nanoclusters can then be used in biomedical, ${ }^{40-49}$ analytical, ${ }^{50-54}$ magnetic, ${ }^{55-60}$ optical $^{61,62}$ and catalytic applications. ${ }^{63-67}$ For example, paramagnetic rare earth elements such as $\mathrm{Gd}^{3+}$ can be easily incorporated into polytungstate (a type of POM) structures to form new molecules. ${ }^{68-70}$ These Gd-containing polytungstates have been shown to be efficient magnetic resonance (MR) imaging contrast agents and exhibited better performances than those of commercial MR imaging contrast agents due to their large molecular weights and rigid structures. ${ }^{71-76}$ In addition, due to the strong X-ray attenuation ability of Gd and $\mathrm{W}$ atoms in gadolinium polytungstates, these nanoclusters could also be used as efficient contrast agents for enhanced signaling in computed tomography (CT) imaging. Therefore, gadolinium polytungstates can act as dual-functional imaging probes in $\mathrm{MR}$ and CT imaging. The combination of MR with CT imaging could offer whole-body imaging capabilities at high spatial resolutions as well as the real-time visualization of nanoparticles in tumor microstructures. In addition to its dual-modal imaging capabilities, gadolinium polytungstates have great potential as radiosensitizers and photothermal absorbing agents for the radiotherapy therapy (RT) and photothermal therapy (PTT) of tumors, respectively. As high Z-materials, gadolinium polytungstates have been shown to accumulate in tumor sites via the enhanced permeability and retention (EPR) effect and are perceived to absorb much more X-ray irradiation than normal tissues can. Thus, gadolinium polytungstates can act as radiosensitizers to improve antitumor radiotherapy therapeutic efficiency. Moreover, after electrochemical or photochemical reduction, reduced gadolinium polytungstates with dark blue colors can efficiently absorb and convert NIR light into heat ${ }^{77}$ for use as PTT agents in the thermal ablation of cancer cells. Most importantly, the ultrasmall size of gadolinium polytungstates enables a rapid renal clearance after treatment and greatly reduces their potential side effects. These unique features could not be replicated by most other hybrid nanocomposite-based theranostic agents. These nanoclusters could be used in the simultaneous multimodal imaging and RT/PTT of cancerous tumors. However, no studies have addressed or considered these potential roles.

To this end, we synthesized bovine serum albumin (BSA)-coated $\mathrm{GdW}_{10} \mathrm{O}_{36}\left(\mathrm{GdW}_{10}\right)$ nanoclusters (NCs) and, for the first time, applied them as multifunctional theranostics for multimodal bio-imaging. We showed that these nanoclusters were highly effective in the in vitro photothermal ablation of cancer cells and in vivo radiotherapy of tumors (Scheme 1). Utilizing their high $r_{1}$ relaxivity and strong X-ray attenuation abilities, GdW $10 @ B S A$ NCs can be successfully used as efficient MR/CT imaging contrast agents to complement multimodal imaging. Moreover, the as-prepared NCs produced significant heat upon $808 \mathrm{~nm}$ laser irradiation. Simultaneously, the NCs generated doseenhanced sensitization effects in RT, which resulted in remarkable in vitro cell damage and in vivo tumor regression. Toxicity screening confirmed that the GdW 10 @BSA NCs were biocompatible and had efficient renal clearance. Our work highlights the potential of gadolinium polytungstates for cancer imaging and therapy and encourages further in-depth investigations of this novel type of POM for biomedical applications.

a

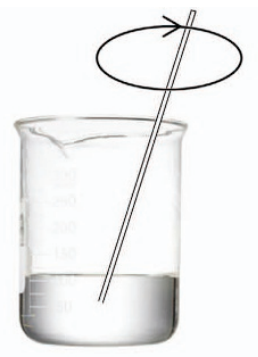

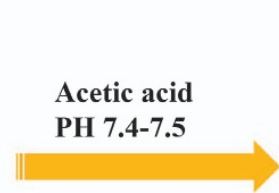

$85{ }^{\circ} \mathrm{C}$

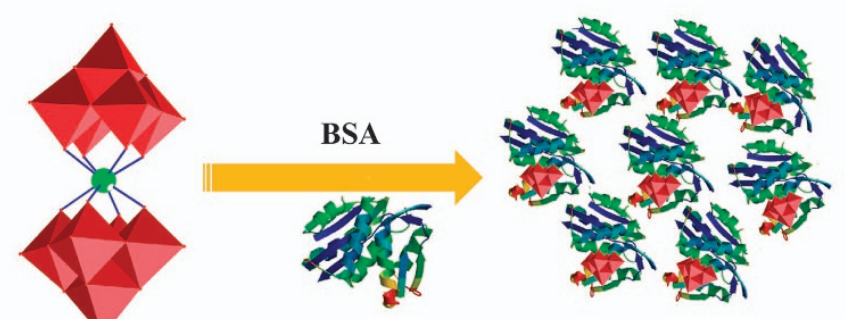

$T_{1}$-weighted images

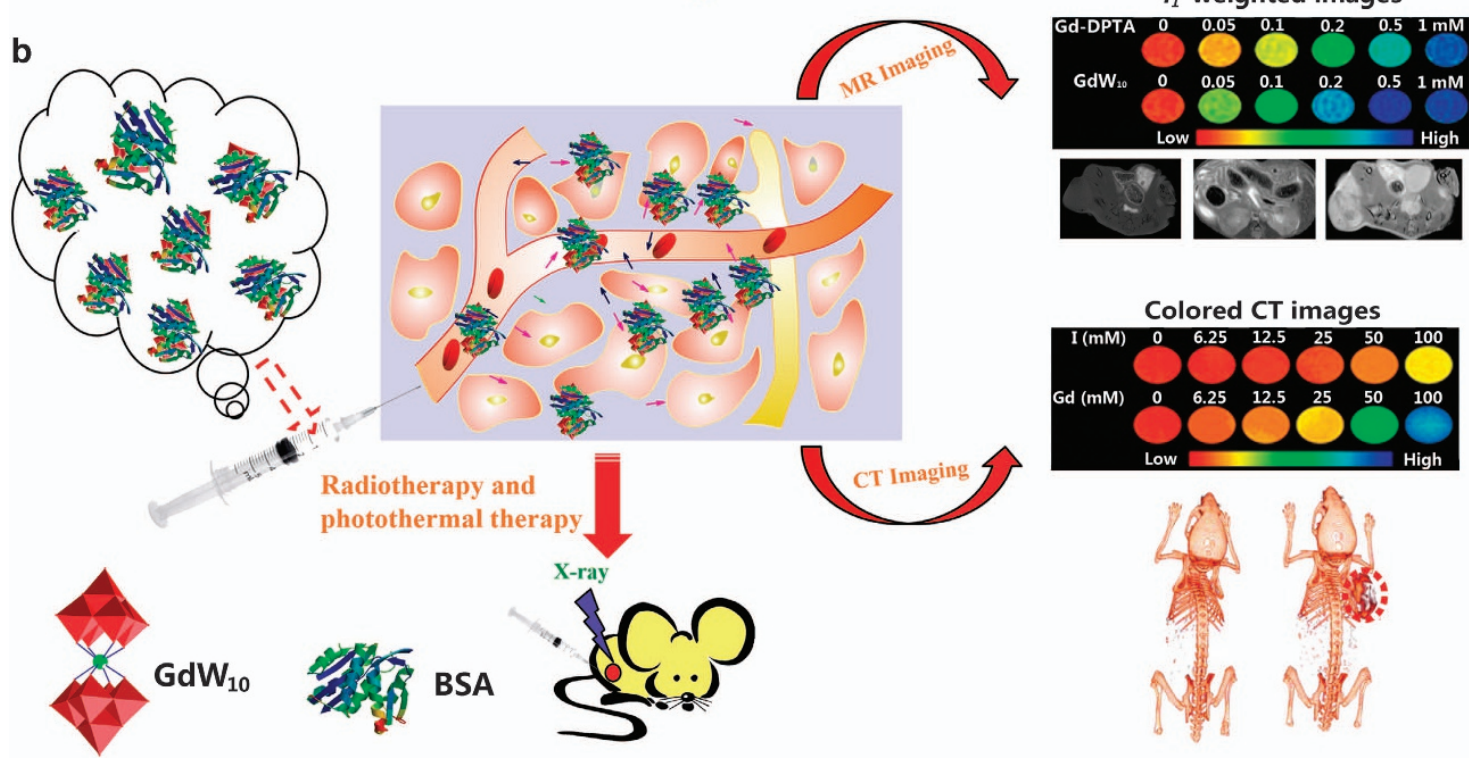

Scheme 1 Schematic illustration of GdW $10 @ B S A$ NCs for dual-modal MR/CT imaging-guided photothermal therapy/radiotherapy of cancer. (a) The synthesis process of $\mathrm{GdW}_{10} @ \mathrm{BSA}$. (b) The application of the as-made $\mathrm{GdW}_{10} @ \mathrm{BSA}$ for bio-imaging and treatment of tumor. 


\section{MATERIALS AND METHODS}

\section{Materials}

All reagents and solvents were of commercial grade and were used without any further purification. $\mathrm{Na}_{2} \mathrm{WO}_{4} \cdot 2 \mathrm{H}_{2} \mathrm{O}$ and $\mathrm{GdCl}_{6} \cdot 6 \mathrm{H}_{2} \mathrm{O}$ were provided by Alfa Aesar Reagent Company (China, Shanghai). Acetic acid was obtained from Beijing Chemical Works (Beijing, China). BSA was adopted from Amresco Company (Shanghai, China). Fetal bovine serum (FBS) and Dulbecco's modified Eagle's medium (DMEM) were adopted from Gibco Company. Calcein-AM (CA), propidium iodide (PI) stain and Cell Counting Kit-8 (CCK-8) were all provided from Dojindo Laboratories. Purified water was used throughout.

\section{Synthesis of $\mathrm{GdW}_{10}$ nanoclusters and GdW 10 @BSA NCs}

The $\mathrm{GdW}_{10}$ NCs were prepared according to a previously described procedure. ${ }^{78}$ In the synthesis, $8.3 \mathrm{~g}(25 \mathrm{mmol})$ of $\mathrm{Na}_{2} \mathrm{WO}_{4} \cdot 2 \mathrm{H}_{2} \mathrm{O}$ was first dissolved in $20 \mathrm{ml}$ of purified water to form a homogeneous solution. The homogeneous solution was adjusted to $\mathrm{pH}$ 7.4-7.5 with acetic acid under magnetic stirring at room temperature. Subsequently, $2 \mathrm{ml}$ of $\mathrm{GdCl}_{6} \cdot 6 \mathrm{H}_{2} \mathrm{O}$ $\left(477.95 \mathrm{~g} \mathrm{~mol}^{-1}, 2.5 \mathrm{mmol}\right)$ aqueous solution was added dropwise to the aforementioned solution under continuous stirring and heated to $85^{\circ} \mathrm{C}$. After cooling to room temperature, crude crystals were isolated. The mixture was dialyzed against purified water for 1 day using a dialysis tube $(2.0 \mathrm{kDa}$ molecular cutoff) to remove impurities. To enhance the biocompatibility of the synthesized $\mathrm{GdW}_{10}$ nanoclusters, BSA was functionalized onto the surfaces of the $\mathrm{GdW}_{10}$ nanoclusters. Briefly, $40 \mathrm{mg}$ BSA was mixed with $2 \mathrm{ml} \mathrm{GdW}_{10}\left(2 \mathrm{mg} \mathrm{ml}^{-1}\right)$ aqueous solution and then stirred for $6 \mathrm{~h}$ at room temperature. The resulting GdW $10 @ \mathrm{BSA}$ NCs were stored at room temperature for further experiments. ${ }^{79-81}$

\section{Characterizations of $\mathrm{GdW}_{10}$ nanoclusters and $\mathrm{GdW}_{10}$-BSA}

The size distributions of the $\mathrm{GdW}_{10}$ NCs and the GdW $10 @ B S A$ NCs were measured on a Nicomp380 ZLS plus ZETADi. The X-ray photoelectron spectra of the $\mathrm{GdW}_{10}$ NCs were obtained on a Kratos AXIS- 165 surface analysis system. An energy dispersive spectrometer (FESEM, Hitachi S-4800) was used to obtain the energy-dispersive X-ray spectra of the $\mathrm{GdW}_{10} \mathrm{NCs}$. The Fourier transform infrared spectra of the $\mathrm{GdW}_{10}$ NCs were measured on a micro-Fourier transform infrared spectrophotometer (iN10-IZ10, Thermo Fisher, Shanghai, China). A Nikon D3100 digital camera was used to capture images. Cell viability was recorded using a microplate reader (SpectraMax M2 MDC, Molecular Devices, Sunnyvale, CA, USA) at an optical absorbance of $450 \mathrm{~nm}$. Induced coupled plasma mass spectrometry (Thermo Elemental X7, Thermal Scientific, Waltham, MA, USA) was employed to determine the concentration of $\mathrm{Gd}^{3+}$ in each organ.

\section{$\mathrm{CT} / \mathrm{MR}$ imaging in vitro}

To test the linearity of the CT signal as a function of the $\mathrm{GdW}_{10} @ \mathrm{BSA} \mathrm{NC}$ concentration, various concentrations $(0,6.25,12.5,25,50$ and $100 \mathrm{~mm})$ of the $\mathrm{GdW}_{10} @ \mathrm{BSA} \mathrm{NC}$ solution and iopromide (Ultravist300, Bayer, Shanghai, China) were separately dispersed in $0.5 \%$ agarose gel. Samples were then aliquoted into $1.5-\mathrm{ml}$ centrifuge tubes for in vitro $\mathrm{CT}$ signal detection. CT images were acquired on the Gamma Medica-Ideas. A Triumph X-O CT system was employed to obtain the Hounsfield unit (HU) values and CT images in vitro. The imaging parameters were as follows: effective pixel size, $50 \mu \mathrm{m} ; 80 \mathrm{kV}, 270 \mu \mathrm{A}$; and field of view, 1024 pixels $\times 1024$ pixels. To detect the MRI signals, the GdW $10 @ \mathrm{BSA}$ NCs and Gd-DTPA at various concentrations $(0,0.05,0.1,0.2,0.5,1 \mathrm{~mm})$ were dispersed in $0.5 \%$ agarose gel. Samples were then aliquoted into $1.5-\mathrm{ml} \mathrm{NMR}$ tubes for MRI signal detection. A 4.7-T MR imaging instrument (Biospec; Bruker; Ettlingen; Germany) was adopted to obtain the $T_{1}$ values and $T_{1}$-weight images of $\mathrm{GdW}_{10} @ B S A$ NCs and Gd-DTPA. The parameters used were as follows: matrix size, $128 \times 128$; field of view, $40 \times 40 \mathrm{~mm}$; and slice thickness, $1.20 \mathrm{~mm}$.

\section{$\mathrm{CT} / \mathrm{MR}$ imaging in vivo}

In vivo $\mathrm{CT}$ images were accomplished on the Gamma Medica-Ideas (Northridge, CA, USA). MDA-MB-231 tumor-bearing $\mathrm{BALB} / \mathrm{c}$ nude mice were intratumorally injected (i.t.) or intravenously injected (i.v.) with the GdW10@BSA NCs. The MDA-MB-231 tumor-bearing BALB/c nude mice were then imaged on the animal X-ray CT instrument (Gamma Medica-Ideas) after the intravenous injection of the $\mathrm{GdW}_{10} @ \mathrm{BSA} \mathrm{NCs}\left(75 \mu \mathrm{mol} \mathrm{kg}^{-1}\right)$. In vivo images were carried out using a Triumph X-O CT system. The imaging parameters of the in vivo CT were as follows: effective pixel size, $50 \mu \mathrm{m} ; 80 \mathrm{kV}$, $270 \mu \mathrm{A}$; and field of view, 1024 pixels $\times 1024$ pixels. For the in vivo MR imaging, the MDA-MB-231 tumor-bearing $\mathrm{BALB} / \mathrm{c}$ nude mice were (i.v.) injected with the $\mathrm{GdW}_{10} @ \mathrm{BSA} \mathrm{NCs}$ and commercially available Gd-DTPA, respectively. After the intravenous injection of the $\mathrm{GdW}_{10} @ \mathrm{BSA} \mathrm{NCs}$ $\left(75 \mu \mathrm{mol} \mathrm{kg}{ }^{-1}\right)$ and Gd-DTPA, the tumor-bearing rat was imaged on a Bruker MR imaging instrument (Bruker; Biospec 70/20; Germany). The MR images were reformed with a microgel system (America). After all experiments were concluded, the animals were euthanized according to the guidelines formulated by the Key Laboratory for Biomedical Effects of Nanomaterials and Nanosafety (Institute of High Energy Physics, CAS).

\section{In vitro photothermal therapy}

After electrochemical reduction, the resulting dark blue $\mathrm{GdW}_{10} @ \mathrm{BSA} \mathrm{NCs}$ efficiently absorbed and converted NIR light to heat. To investigate the photothermal effect of reduced $\mathrm{GdW}_{10} @ \mathrm{BSA} \mathrm{NCs}, 1 \mathrm{mg} \mathrm{ml}^{-1}$ of reduced GdW $10 @ B S A$ NCs was irradiated with an 808-nm laser at a power density of $1 \mathrm{~W} \mathrm{~cm}{ }^{-2}$. The $\mathrm{NaCl}$ solution was used as a negative control group. An IR thermal camera was used to detect temperature changes in the reduced $\mathrm{GdW}_{10} @ \mathrm{BSA} \mathrm{NCs}$ and the $\mathrm{NaCl}$ solution at each time point. In addition, to test the photothermal effect of the reduced GdW $10 @ B S A$ NCs on cancer cells, HeLa cells were incubated in a six-well culture plate at a density of $1 \times 10^{6}$ per well. Then, different concentrations of the reduced GdW $10 @ \mathrm{BSA}$ NCs $(0,62.5$, 125, 250, 500 and $1000 \mu \mathrm{g} \mathrm{ml}^{-1}$ ) were added to the HeLa cells. After $4 \mathrm{~h}$, the culture medium was replaced with fresh DMEM. The cells incubated with the reduced $\mathrm{GdW}_{10} @ \mathrm{BSA}$ NCs were irradiated by an 808-nm laser lamp at a power density of $1 \mathrm{~W} \mathrm{~cm}{ }^{-2}$ for $10 \mathrm{~min}$. After incubating for an additional $12 \mathrm{~h}$, the culture medium was washed twice with PBS. Subsequently, the calcein-AM (CA)/propidium iodide (PI) stain applied for $15 \mathrm{~min}$. Finally, the cell samples were washed twice with PBS, and an inverted fluorescence microscope (Olympus X73, Tokyo, Japan) was employed to obtain fluorescent images.

\section{$\mathrm{GdW}_{10}$-enhanced radiotherapy in vivo}

All animals were purchased, maintained and killed the under protocols approved by the Key Laboratory for Biomedical Effects of Nanomaterials and Nanosafety (Institute of High Energy Physics, CAS). The BEL-7402 tumors were generated by the subcutaneous implantation of $1.0 \times 10^{6}$ BEL-7402 cells suspended in $100 \mu \mathrm{l}$ phosphate-buffered saline (PBS) into the right rear legs of $16 \mathrm{BALB} / \mathrm{c}$ female mice. The mice were assigned to four groups based on treatment: (a) PBS injection; (b) GdW $10 @ B S A$ NCs i.t. injection; (c) X-ray only; and (d) $\mathrm{GdW}_{10} @ \mathrm{BSA}$ NCs+X-ray when the tumor volume reached $\sim 75 \mathrm{~mm}^{3}$. For groups $\mathrm{b}$ and $\mathrm{d}$, the BEL-7402 tumor-bearing BALB/c nude mice were intratumorally injected with $20 \mu \mathrm{l} \mathrm{GdW}_{10} @ \mathrm{BSA} \mathrm{NCs}\left(2 \mathrm{mg} \mathrm{ml}^{-1}\right)$. As the control group, $20 \mu$ of phosphate buffer saline was intratumorally injected into each mouse. The mice in groups $\mathrm{c}$ and $\mathrm{d}$ were irradiated by X-ray (6 Gy) to receive radiotherapy. After the treatments, the mice weights and tumor volumes were recorded every 2 or 3 days using a vernier caliper. At the end of the experiment, all BEL-7402 tumor-bearing BALB/c nude mice were killed under protocols approved by the Key Laboratory for Biomedical Effects of Nanomaterials and Nanosafety (Institute of High Energy Physics, CAS). The main organs and tumors of each mice were collected and stained with hematoxylin \& eosin (H\&E) for tissue lesion analyses.

\section{Cytotoxicity and cellular of GdW $10 @ B S A$ NCs}

16HBE cells (bronchial epithelioid cells) and HeLa cells (human cervical cancer cells) were grown in 96-well culture plates with high-glucose DMEM supplemented with $10 \% \mathrm{FBS}(\mathrm{GIBCO})$ at $37^{\circ} \mathrm{C}$ under a humidified $5 \% \mathrm{CO}_{2}$ atmosphere. Cell viabilities were evaluated using the Cell Counting Kit- 8 (CCK-8, Dojindo Laboratories, Shanghai, China) assay. The evaluation was performed as follows. Cells were cultured in a 96-well plate at a density of 
$2 \times 10^{4}$ cells per well. The cells were washed twice with PBS $(\mathrm{pH}=7.4)$ and incubated with different concentrations of $\mathrm{GdW}_{10} @ \mathrm{BSA} \mathrm{NCs}$ for $24 \mathrm{~h}$. Subsequently, $10 \mu \mathrm{l}$ of fresh CCK- 8 was added into the culture medium, and the cells were incubated for an additional $1 \mathrm{~h}\left(37^{\circ} \mathrm{C}\right.$ under $\left.5 \% \mathrm{CO}_{2}\right)$. Finally, the absorbance was measured at $450 \mathrm{~nm}$ using a microplate reader (Thermo Scientific, Multiscan MNK3, Waltham, MA, USA).

To observe the cellular absorption of GdW $\mathrm{GW}_{10} @ \mathrm{BSA} \mathrm{NCs,}$ 16HBE cells and HeLa cells were cultured in a six-well plate at a density of $1 \times 10^{6}$ cells per well, respectively. Then, the $16 \mathrm{HBE}$ cells and HeLa cells were treated with GdW $10 @ B S A N C s\left(400 \mu \mathrm{g} \mathrm{ml}^{-1}\right)$ for $24 \mathrm{~h}$. Subsequently, the cells were washed twice with PBS and stained with CA-PI for $15 \mathrm{~min}$. Then, the cells were washed twice with PBS, and fluorescent images were acquired with an inverted fluorescence microscope (Olympus X73, Japan).

\section{Biodistribution and pathology analysis}

Twenty-one BALB/c female mice were purchased, maintained and killed after the intravenous injection of PBS and $\mathrm{GdW}_{10} @ \mathrm{BSA}$ NCs at different time points using protocols approved by the Key Laboratory for Biomedical Effects of Nanomaterials and Nanosafety (Institute of High Energy Physics, CAS). The major tissues and organs, including heart, liver, spleen, lungs, kidneys and blood, were weighed and dissolved in $5 \mathrm{ml}$ of concentrated nitric acid solution $\left(\mathrm{HNO}_{3}, \mathrm{BV}\right.$-III). The samples were then heated to $180^{\circ} \mathrm{C}$ for $2 \mathrm{~h}$. Subsequently, $2 \mathrm{ml}$ concentrated nitric acid solution was added. When the solution cleared and cooled to room temperature, $1 \mathrm{ml} \mathrm{H}_{2} \mathrm{O}_{2}$ solution was added to neutralize the nitric acid solution. The resulting solution was diluted with $2 \% \mathrm{HNO}_{3}$ $\left(V / V_{0}\right)$ to $5.0 \mathrm{ml}$ and analyzed by induced coupled plasma mass spectrometry (Thermo Elemental X7, USA) to determine the concentration of $\mathrm{Gd}^{3+}$ in each organ or tissue. The BALB/c female mice were killed after the intravenous injection of $200 \mu \mathrm{l}$ PBS and $\mathrm{GdW}_{10} @ \mathrm{BSA}$ NCs $\left(0.02 \mathrm{M}, 75 \mu \mathrm{mol} \mathrm{kg}^{-1}\right)$ solutions at days 1 and 7. Organs, including heart, liver, spleen, lungs and kidneys, were obtained. These organs were weighed, set and fixed in $4 \%$ paraformaldehyde solution, processed in paraffin, sectioned and stained with H\&E. The representative H\&E images were analyzed with an inverted fluorescence microscope (Olympus X73, Japan).

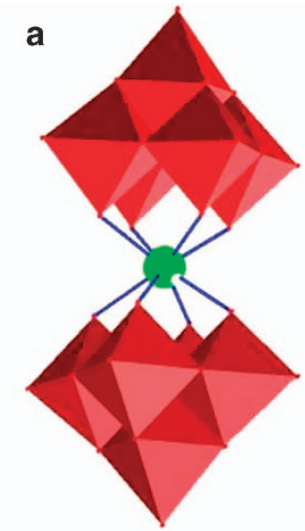

b
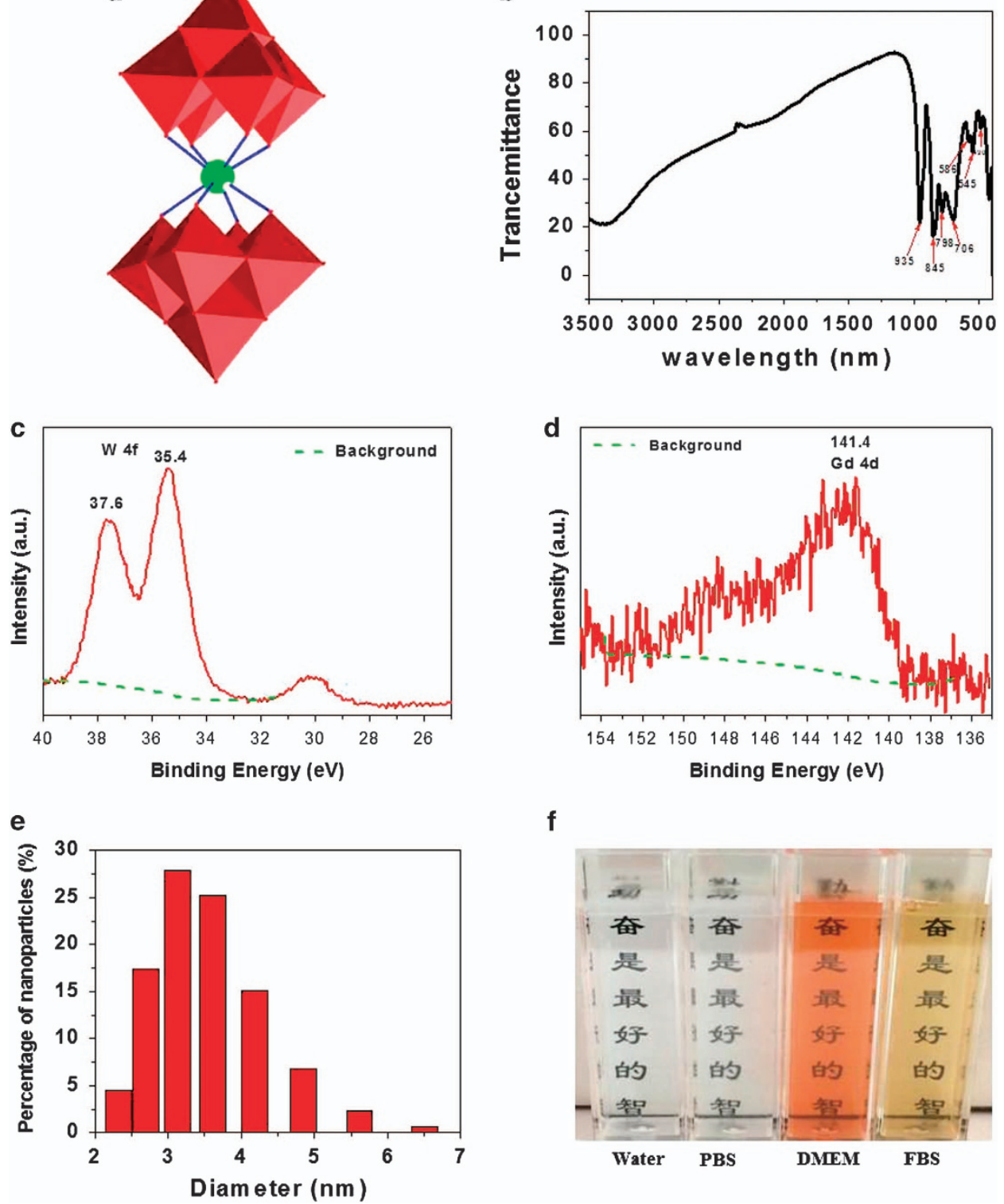

f

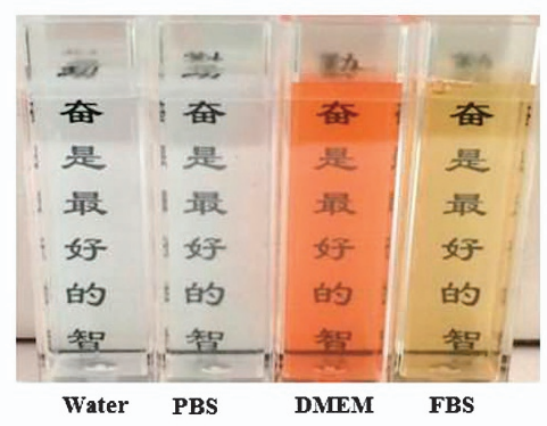

Figure 1 (a) Schematic illustration of the structure of GdW 10 NCs; (b) FT-IR spectra of as-fabricated GdW 10 NCs, FT-IR data in $\mathrm{cm}^{-1}: 935$ (s), 845 (s), 798 $(\mathrm{m}), 706(\mathrm{~m}), 586(\mathrm{w}), 545(\mathrm{~m}), 490(\mathrm{w}) ;(\mathrm{c}) \mathrm{W} 4 \mathrm{f}$ and (d) Gd 4d XPS spectra of the synthesized GdW 10 NCs. (e) The hydrodynamic diameter of the as-made $\mathrm{GdW}_{10}-\mathrm{BSA}$ nanoclusters. (f) The photograph of $\mathrm{GdW}_{10} @ \mathrm{BSA}$ nanoclusters dissolved in different solutions. 
Blood hematology and biochemistry analysis

Blood samples were harvested from the mice fundus artery after the intravenous administration of $200 \mu \mathrm{l}$ PBS and $\mathrm{GdW}_{10} @ \mathrm{BSA}$ NCs $\left(0.02 \mathrm{M}, 75 \mu \mathrm{mol} \mathrm{kg}^{-1}\right)$ solutions, respectively, at $5 \mathrm{~h}$, and at days 1,3 and 7. One milliliter of blood was obtained from each mouse, $0.5 \mathrm{ml}$ of which was centrifuged at 1500 r.p.m. for $5 \mathrm{~min}$ to obtain blood plasma. One-hundredmicroliter blood samples in solution were treated with anticoagulant (potassium EDTA) for routine analysis. Blood hematology and biochemistry analyses were accomplished at the Animal Department of Peking University Medical Laboratory.

\section{RESULTS AND DISCUSSION}

Structure diagram and characterization of $\mathrm{GdW}_{10}$ nanoclusters $\mathrm{GdW}_{10}$ nanoclusters were prepared according to a previously described method. ${ }^{78}$ As illustrated in Figure 1a, a $\mathrm{Gd}$ atom is sandwiched by two lacunary $\mathrm{W}_{5} \mathrm{O}_{18}$ caps to form a $\mathrm{GdW}_{10}$ nanocluster. The as-synthesized $\mathrm{GdW}_{10}$ was characterized using Fourier transform infrared (FT-IR) analysis; the resulting spectrum correlated with those of previous reports (Figure 1b). ${ }^{78}$ This was further confirmed by energy-disperse X-ray spectra, indicating the successful formation of $\mathrm{GdW}_{10}$ nanoclusters (Supplementary Figure S1). Furthermore, X-ray photoelectron spectroscopy analysis was carried out to determine the composition and chemical state of the as-prepared sample. The two strong peaks at 35.4 and $37.6 \mathrm{eV}$ corresponded with the $\mathrm{W}_{4 \mathrm{f} 7 / 2}$ and $\mathrm{W}_{4 \mathrm{f} 5 / 2}$ states of $\mathrm{W}^{6+}$, respectively (Figure 1c). The peak at $141.4 \mathrm{eV}$ was ascribed to the $\mathrm{Gd}_{4 \mathrm{~d}}$ state of $\mathrm{Gd}^{3}$ + (Figure 1d). No other impurities were observed, indicating the high purity of the as-prepared $\mathrm{GdW}_{10}$ clusters. The as-obtained $\mathrm{GdW}_{10}$ nanoclusters were easily dissolved in water. To improve their biocompatibility and solubility in physiological solutions, the $\mathrm{GdW}_{10}$ nanoclusters were further functionalized with BSA to form a hybrid complex through physical adsorption. The hydrodynamic diameter of the formed $\mathrm{GdW}_{10}$-BSA nanoclusters was measured by dynamic light scattering and were $\sim 3.5 \mathrm{~nm}$ in water (Figure 1e), which is below the commonly recognized threshold for kidney filtration $(\sim 5.5 \mathrm{~nm})$. This feature may increase the clearance rates in biosystems and minimize the potential toxic side effects. Moreover, the BSAmodified $\mathrm{GdW}_{10}$ nanoclusters exhibited good solubility in various physiological solutions (Figure 1f).

\section{MR imaging of $\mathrm{GdW}_{10} @ \mathrm{BSA} \mathrm{NCs}$ in vitro and in vivo}

Ideal nano-theranostic systems should possess multimodal bio-imaging capabilities for precise spatial and temporal-specific tracking in vivo. This would help guide and monitor the therapeutic process and response, improve therapeutic outcomes and reduce the associated side effects. To assess the MR contrast performance of the $\mathrm{GdW}_{10} @ \mathrm{BSA}$ NCs in vitro, the contrast effect of the GdW $\mathrm{GW}_{10} @ \mathrm{BSA} \mathrm{NCs}$ at different $\mathrm{Gd}^{3+}$ concentrations $(0.05-1.0 \mathrm{~mm})$ was examined with a 4.7-T MR imaging instrument. For increasing $\mathrm{Gd}^{3+}$ concentrations, the $T_{1}$-weighted $\mathrm{MR}$ imaging intensity substantially brightened (Figure 2a). The same concentration gradient of $\mathrm{GdW}_{10} @ \mathrm{BSA} \mathrm{NCs}$ was investigated to determine the specific relaxivity coefficient $\left(r_{1}\right)$, which was calculated from the slope of a linear-fitted plot of $1 / T_{1}$ versus Gd concentration. As shown in Figure 2b, a good linear relationship was observed; the slope, that is, the $r_{1}$ value for the $\mathrm{GdW}_{10} @$ BSA NCs, was calculated to be $9.45 \mathrm{~s}^{-1} \mathrm{~mm}^{-1}$, which was much higher than that of conventional Gd-DTPA $\left(3.90 \mathrm{~s}^{-1} \mathrm{~mm}^{-1}\right)$ at the same concentration. These results indicated that the GdW $10 @ B S A$ NCs exhibited a positive signal-enhancement ability and could potentially serve as a $T_{1}$-weighted $\mathrm{MR}$ imaging contrast agent. Encouraged by this performance in vitro, we next evaluated the a

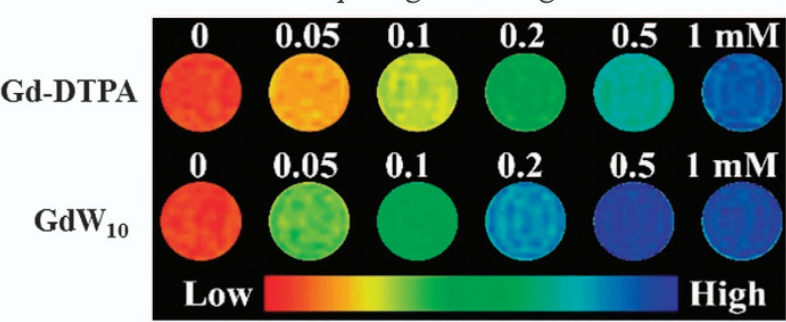

b

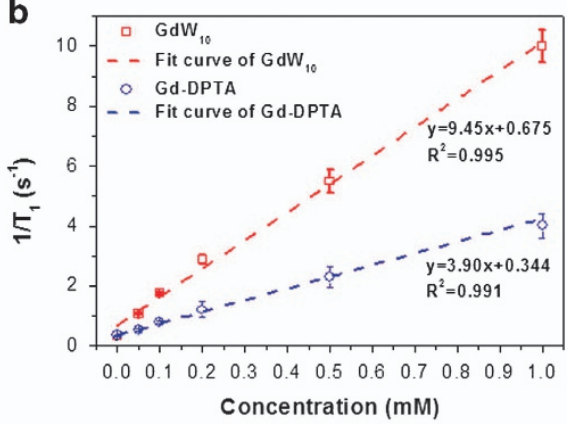

C

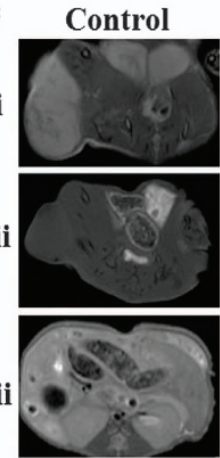

$5 \mathrm{~min}$

$0.5 \mathrm{~h}$
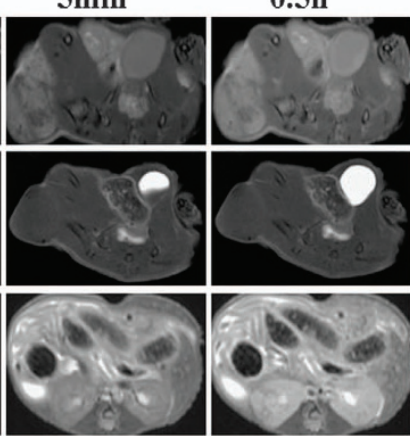

$1.0 \mathrm{~h}$

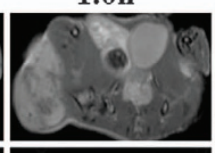

$1.5 \mathrm{~h}$

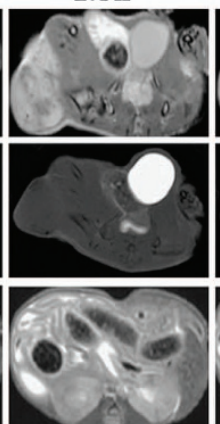

$2.0 \mathrm{~h}$

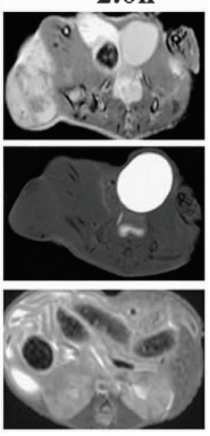

Figure 2 (a) $T_{1}$-weighted MRI images of commercially available Gd-DTPA and the as-synthesized GdW $10 @ \mathrm{BSA}$ NCs; (b) relaxation rate $\left(1 / T_{1}, R_{1}\right)$ at various

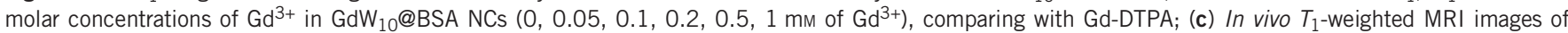
BALB/c mice bearing MDA-MB-231 tumor before and after i.v. injection of the as-made GdW $_{10} @ B S A$ NCs and commercially available Gd-DTPA.

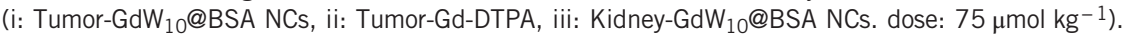


application of the nanoclusters as MR imaging contrast agents in vivo. MDA-MB-231 tumor-bearing nude BALB/c mice were intravenously administered with a PBS solution of $\mathrm{GdW}_{10} @ \mathrm{BSA} \mathrm{NCs}$ and the $T_{1}$-weighted MRI images were acquired before and at 5, 30, 60, 90 and $120 \mathrm{~min}$ after injection (Figure 2c). Before the intravenous injection of the GdW $10 @ B S A$ NCs, the tumor appeared dark and homogeneous. After the i.v. administration of the $\mathrm{GdW}_{10} @ \mathrm{BSA} \mathrm{NCs}$, the signal at the tumor site was significantly enhanced and the tumor appeared inhomogeneous. No obvious changes were observed in tumors after the i.v. administration of Gd-DTPA due to its smaller molecular size and quick clearance from the tumor. At $2 \mathrm{~h}$ after the injection of NCs, the MR signal of the nanocluster injection was two times higher than that of the Gd-DTPA (Supplementary Figure S2), demonstrating that the GdW $10 @ B S A$ NCs could efficiently and passively target the tumor site with a longer residence time compared with the commercial MR imaging contrast agent. In addition, significant signal enhancements in the kidney after the i.v. injection of $\mathrm{GdW}_{10} @ \mathrm{BSA}$ NCs were observed (Figure 2c), which indicated that the ultrasmall-sized GdW $10 @ B S A$ NCs could be cleared via renal excretions, which greatly enhances their clearance rate. This feature of the $\mathrm{GdW}_{10} @ \mathrm{BSA}$ NCs minimizes their potential side effects and increases their suitability for clinical use.

\section{CT imaging of the synthesized GdW $10 @ B S A$ NCs in vitro and in vivo}

In addition to their MR imaging application due to its high- $Z$ elements (that is, the W and Gd atoms), these $\mathrm{GdW}_{10} @ \mathrm{BSA}$ NCs may have a strong X-ray attenuation ability. Thus, these nanoclusters could be used as contrast agents for CT imaging, which is one of the most commonly used imaging tools for medical diagnoses. CT imaging can be used to acquire high-resolution 3D structural details of the whole body. For the first time, we evaluated the potential of the GdW $10 @ B S A$ NCs as CT contrast agents. Varied concentrations of GdW $10 @ B S A$
NCs solution were used to obtain X-ray phantom images in vitro. Figure 3a reveals that the X-ray CT images become gradually brighter with increasing nanocluster concentration. The CT values, that is, HUs, increased linearly with $\mathrm{GdW}_{10} @ \mathrm{BSA} \mathrm{NC}$ concentration (Figure 3b). The measured X-ray CT absorption coefficient of the GdW $10 @ B S A ~ N C s$ was 19.2 $\mathrm{HU} \mathrm{m}^{-1}$, which was three times higher than that of commercial iopromide $\left(6.09 \mathrm{HU} \mathrm{mM}^{-1}\right)$, indicating the good contrast efficacy of the $\mathrm{GdW}_{10} @ \mathrm{BSA} \mathrm{NCs}$ for CT imaging. This could be due to the $\mathrm{W}$ and $\mathrm{Gd}$ atoms having higher $\mathrm{X}$-ray absorption efficiencies than I atoms (W, $4.44 \mathrm{~cm}^{2} \mathrm{~g}^{-1}$; Gd, $3.11 \mathrm{~cm}^{2} \mathrm{~g}^{-1}$; and I, 1 . $94 \mathrm{~cm}^{2} \mathrm{~g}^{-1}$ at $\left.100 \mathrm{keV}\right) .{ }^{82,83}$ We next evaluated the feasibility of using the nanoclusters for in vivo CT imaging in MDA-MA-231 tumorbearing nude mice. After the i.t. injection of GdW $10 @ B S A$ NCs in physiological saline $(0.02 \mathrm{M}, 50 \mu \mathrm{l})$, the signal at the tumor site was immediately and clearly seen. This indicates that the $\mathrm{GdW}_{10} @ \mathrm{BSA}$ NCs have great potential as efficient contrast agents for tumor CT imaging (Figure 3c). Thus, GdW $10 @ B S A$ NCs have remarkable potential as dual-mode contrast agents for MR/CT imaging.

\section{Photothermal evaluation of the as-fabricated GdW $10 @ B S A$ NCs in vitro}

We next pursued the application of $\mathrm{GdW}_{10} @ \mathrm{BSA}$ NCs as therapeutics for cancer therapy. Although many POMs have been used as drugs for the treatment of HIV and other diseases, ${ }^{84,85}$ the use of GdW $10 @ B S A$ $\mathrm{NCs}$ as photothermal absorbing agents and radiosensitizers for photothermal therapy and tumor radiotherapy has not been reported. After electrochemical reduction, the transparent GdW $_{10} @ B S A$ NCs changed to a dark blue color. The UV-Vis absorption spectrum of the reduced $\mathrm{GdW}_{10} @ \mathrm{BSA}$ NCs showed a strong absorbance around $800 \mathrm{~nm}$ (Figure 4a), which was attributed to an intervalence chargetransfer transition between $\mathrm{W}^{6+}$ and $\mathrm{W}^{5+}$. The high NIR absorption capability of the reduced $\mathrm{GdW}_{10} @ \mathrm{BSA}$ NCs motivated us to investigate a
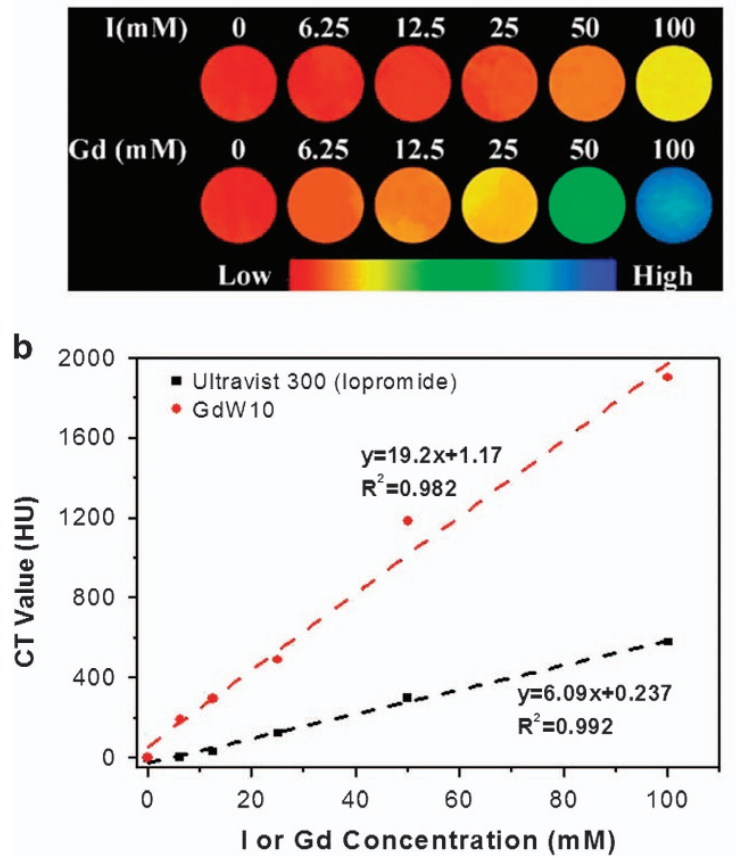

C

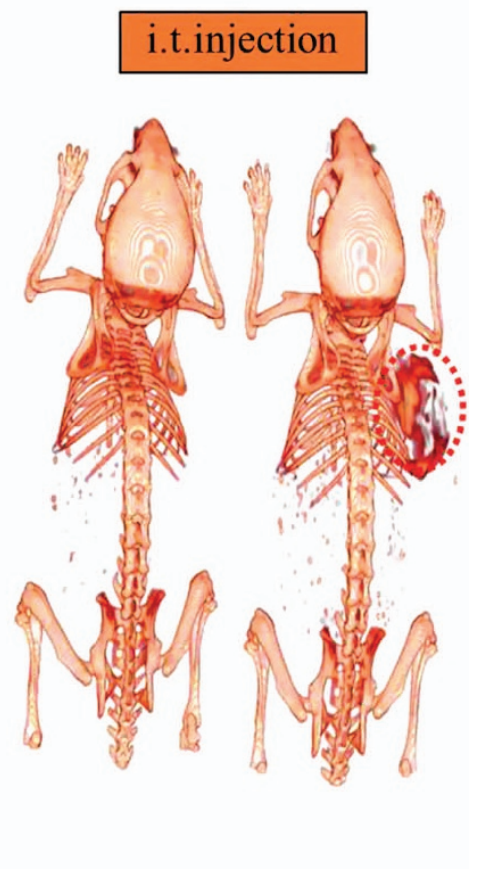

Figure 3 (a) In vitro CT phantom images of lopromide and GdW $10 @ B$ BA NCs with different concentrations (0, 6.25, 12.5, 25, 50 and 100 mm of Gd $\left.{ }^{3+}\right)$. (b) Hountsfied Unit values of $\mathrm{GdW}_{10} @ \mathrm{BSA} \mathrm{NCs}$ and lopromide as the function of their concentrations. (c) In vivo CT images of a BALB/c mice bearing MDA-

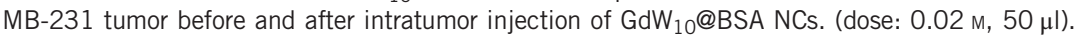


a

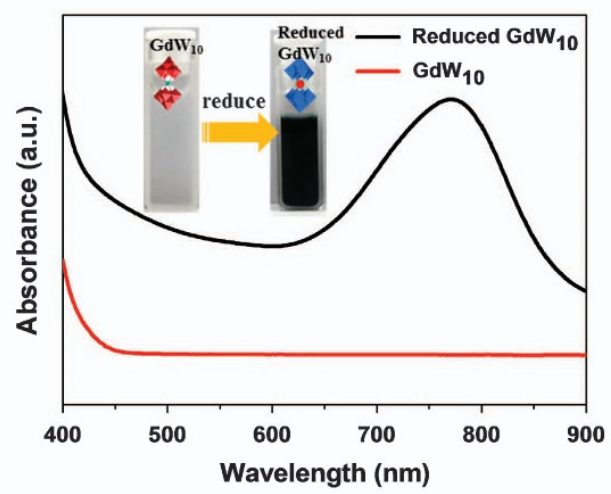

c

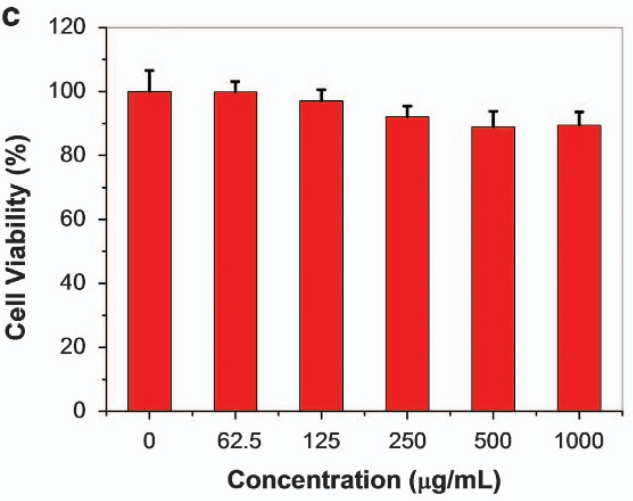

e

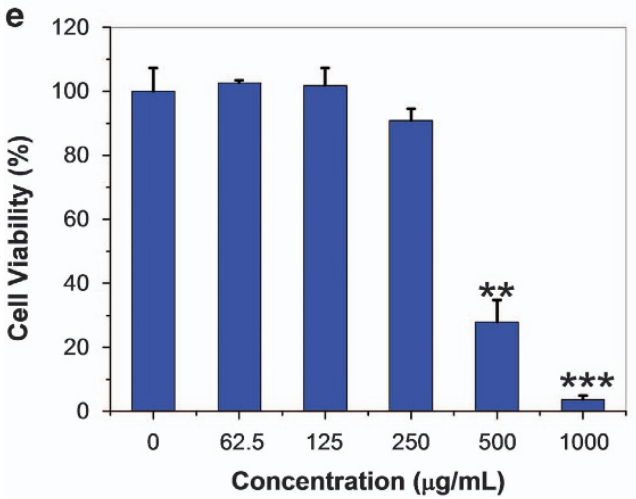

b

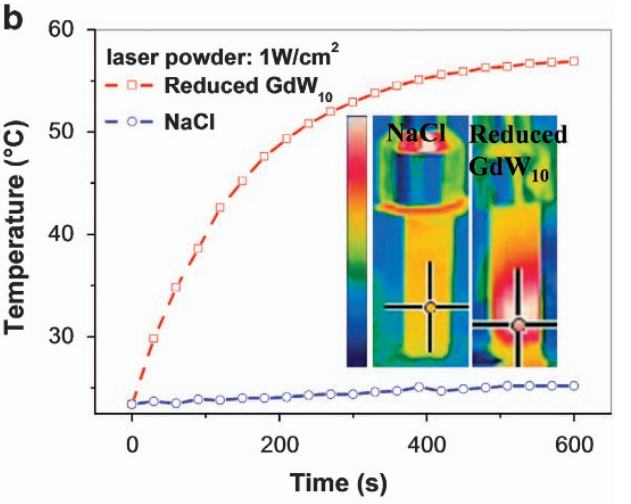

d

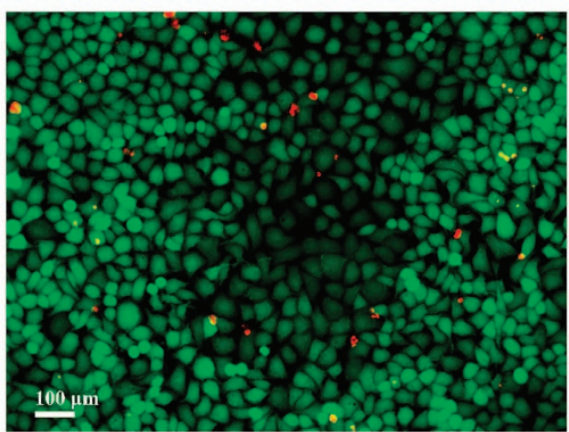

f

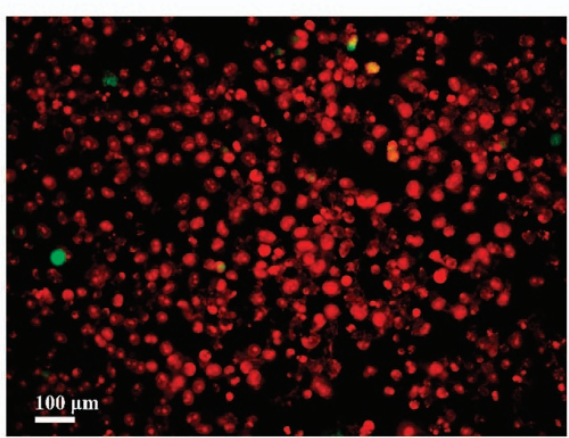

Figure 4 (a) UV-vis absorption spectrum of $\mathrm{GdW}_{10} \mathrm{NCs}$ solution before and after the reduction. Inset: the corresponding digital images of before and after the reduction. (b) The temperature evaluation of pure $\mathrm{NaCl}$ solution and reduced $\mathrm{GdW}_{10} @ \mathrm{BSA} / \mathrm{NCs}\left(1 \mathrm{mg} \mathrm{ml}^{-1}\right)$ under the irradiation of $808 \mathrm{~nm}$ laser with a power density of $1 \mathrm{~W} \mathrm{~cm}^{-2}$ as a functional of irradiation time (0-10 min); (c) cell viability assays on Hela cells incubated with reduced GdW $10 @ B S A / N S$ solution $\left(0,62.5,125,250,500\right.$ and $\left.1000 \mu \mathrm{g} \mathrm{ml} \mathrm{l}^{-1}\right)$ (c) before and (e) after $808 \mathrm{~nm}$ laser $\left(1 \mathrm{~W} \mathrm{~cm}{ }^{-2}, 10 \mathrm{~min}\right) ;$ live-dead cell staining studies using Calcein-AM and PI on Hela cells incubated with reduced $\mathrm{GdW}_{10} @ \mathrm{BSA} / \mathrm{NS}$ solution $\left(1000 \mu \mathrm{g} \mathrm{ml} \mathrm{l}^{-1}\right)$ (d) before and (f) after 10-min irradiation with $808 \mathrm{~nm}$ laser $\left(1 \mathrm{~W} \mathrm{~cm}^{-2}, 10 \mathrm{~min}\right)$. Error bars were based on s.d. of six parallel samples. $P$-values were obtained by the Student's test: ${ }^{* *} P<0.01,{ }^{* * *} P<0.001$.

the NIR photothermal properties that enable the nanoclusters to function as photothermal absorbing agents for NIR-triggered PTT. To assess these properties, the changes in temperature of aqueous dispersions of reduced GdW $10 @ B S A$ NCs $\left(1 \mathrm{mg} \mathrm{ml}^{-1}\right)$ were measured under $808 \mathrm{~nm}$ NIR laser irradiation $\left(1 \mathrm{~W} \mathrm{~cm}^{-2}, 10 \mathrm{~min}\right) . \mathrm{A} \mathrm{NaCl}$ solution was used as the control (Figure 4b). The temperature of the $\mathrm{GdW}_{10} @ B S A$ NCs samples raised increased with the irradiation time and reached up to $55^{\circ} \mathrm{C}$ after $10 \mathrm{~min}\left(1 \mathrm{~W} \mathrm{~cm}^{-2}\right)$. The temperature of the $\mathrm{NaCl}$ solution only showed a mild temperature change (a change of $\sim 5^{\circ} \mathrm{C}$ ). These results demonstrated that the $\mathrm{GdW}_{10} @ \mathrm{BSA} \mathrm{NCs}$ can rapidly and efficiently convert NIR light into heat. Due to the good photothermal heating effect, the photothermal therapeutic effects of reduced $\mathrm{GdW}_{10} @ \mathrm{BSA} \mathrm{NCs}$ on HeLa cells in vitro were studied. After incubation with reduced $\mathrm{GdW}_{10} @ \mathrm{BSA} \mathrm{NCs}$, there was no noticeable cell apoptosis, even at concentrations up to $1.0 \mathrm{mg} \mathrm{ml}^{-1}$. The HeLa cell viability remained greater than $90 \%$ (Figure $4 \mathrm{c}$ and Supplementary Figure S3). In contrast, after irradiation with $808 \mathrm{~nm}$ laser at a power density of $1 \mathrm{~W} \mathrm{~cm}^{-2}$ for $10 \mathrm{~min}$, the cell viability substantially decreased to $5 \%$, indicating the efficient photothermal ablation of cancer cells (Figure 4e). These results were visually confirmed by live-dead cell staining images, which showed almost no cells survived after the irradiation (Figures $4 \mathrm{~d}$ and f). Therefore, our results suggested that the $\mathrm{GdW}_{10} @ \mathrm{BSA} \mathrm{NCs}$ could be used as an efficient agent for the PTT of cancer cells. 

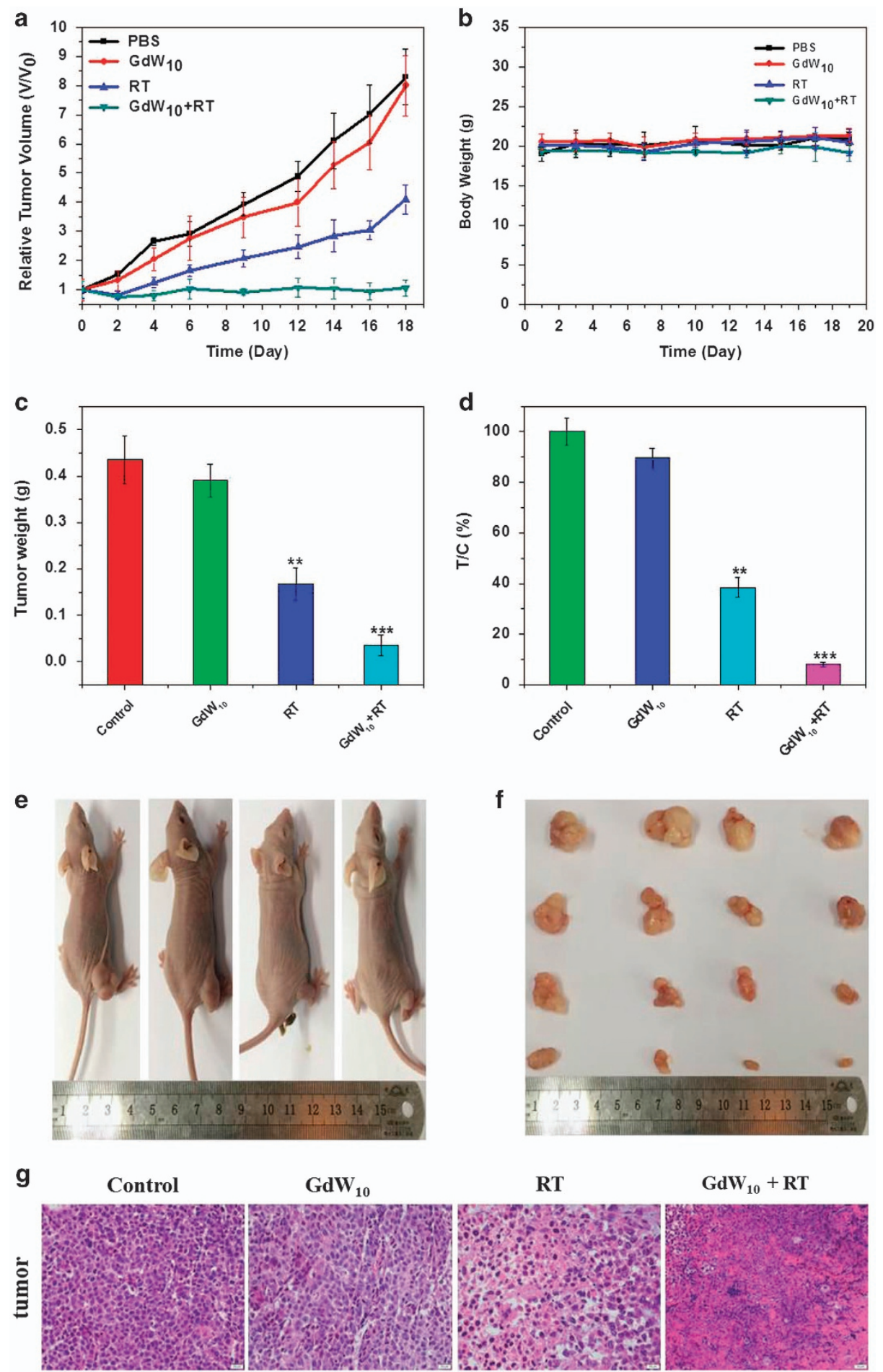

Figure 5 (a) The relative tumor volume curves of different group mice after different treatments: (i) PBS injection; (ii) GdW $10 @ B S A$ NCs i.t. injection; (iii) X-ray only; (iv) GdW $10 @ B S A ~ N C s+X$-ray. (b) The body weight of different group BEL-7402 tumor-bearing mice after various administrations. (c) Average weight of tumors collected from each group tumor-bearing mice after radiotherapy. (d) The tumor inhibition rate of different group BEL-7402 tumor-bearing mice. (e) Representative images of different group BEL-7402 tumor-bearing mice after different administrations at the end of radiotherapy. (f) Photos of tumors collected from each group BEL-7402 tumor-bearing mice after various administrations. (g) H\&E stained images of tumors collected from different group mice. Error bars were based on s.d. of four parallel specimens. $P$-values were calculated by the Student's test: ${ }^{* *} P<0.01,{ }^{* * *} P<0.001$.

In vivo as-fabricated $\mathrm{GdW}_{10} @ \mathrm{BSA} \mathrm{NCs}$-enhanced radiotherapy of tumor-bearing nude mice

In addition to their PTT applications, the $\mathrm{GdW}_{10} @ \mathrm{BSA}$ NCs could be used as radiosensitizers for enhanced RT therapies of tumors due to the nanoclusters containing a large number of high $\mathrm{Z}$ elements in each $\mathrm{GdW}_{10} @ \mathrm{BSA}$ particle (Gd and W atoms). RT is one of the most commonly used treatments for cancer therapy and employs high energy X-ray or $\gamma$-ray radiation to kill cancer cells without any depth 
restrictions. For the first time, we assessed the feasibility of $\mathrm{GdW}_{10} @ \mathrm{BSA} \mathrm{NCs}$ as radiosensitizers for the RT of tumors. BEL-7402 tumor-bearing nude mice were divided into four groups (a) PBS only; (b) GdW $10 @ B S A$ NCs only; (c) RT only; and (d) GdW 10 @BSA NCs + RT. The tumor volume changes and body weights of all mice were recorded as functions of time (Figures $5 \mathrm{a}$ and b). As shown in Figure 5a, at 18 days after treatment, tumors in groups a and b grew rapidly with relative tumor volume changes $\left(V / V_{0}\right)$ of $8.29 \pm 0.948$ and $7.993 \pm 1.042$, respectively. This indicated that the single use of $\mathrm{GdW}_{10} @ \mathrm{BSA}$ NCs without X-ray radiation had negligible effects on tumor growth (Supplementary Table S2). The mice treated with RT alone exhibited tumor growth inhibition, as indicated by the relative tumor volume change of $61.49 \%$ $\left(V / V_{0}=4.103 \pm 0.496\right)$ after 18 days of treatment (Figures $5 \mathrm{c}$ and $\left.\mathrm{d}\right)$. The most efficient tumor growth delay was achieved using the treatment of $\mathrm{GdW}_{10} @ \mathrm{BSA} \mathrm{NCs}+\mathrm{RT}$ (group d). As shown in Figures $5 \mathrm{e}$ and $\mathrm{f}$, compared with RT alone, the tumors in group $\mathrm{d}$ were thoroughly eliminated at 4 days after treatment without recurrence in the subsequent 14 days, thus indicating the efficient sensitization effect of $\mathrm{GdW}_{10} @ \mathrm{BSA}$ NCs on RT. These effects were confirmed using H\&E staining (Figure $5 \mathrm{~g}$ ). The HE staining images of tumor slices collected at 18 days after the treatments indicated that most of the tumor cells were destroyed under the $\mathrm{GdW}_{10} @ B S A \mathrm{NCs}$ $+\mathrm{RT}$ treatment. Tumor cells treated with $\mathrm{GdW}_{10} @ \mathrm{BSA}$ NCs or X-rays alone resulted in partial damages to the tumor tissues, which further showed the distinct $\mathrm{GdW}_{10} @ \mathrm{BSA}$ NCs-enhanced RT effects.

\section{Cytotoxicity}

Theranostic safety is an important factor for evaluating nanocluster biological applications. Firstly, we evaluated the stability of GdW $10 @ B S A$ NCs at various pH value. No obvious changes have been noticed, indicating its well stability at current condition (Supplementary Figures S8 and S9). Next, to determine the biocompatibility of $\mathrm{GdW}_{10} \mathrm{NCs}$, the toxicity of the NCs was evaluated by various in vivo experiments, including studying changes in animal behavior, body weight, biodistribution, H\&E staining, and blood biochemistry. After thirty days of infection, no mice had died and no obvious signs of abnormal changes in body weight, activity, eating, and drinking were observed. The biodistribution results showed that the $\mathrm{GdW}_{10}$ NCs mainly accumulated in the kidneys and blood (Supplementary Figure S4). Hematological and serum chemistry analyses revealed that all parameters, such as renal function markers (CRE, BUN), were within normal ranges (Supplementary Figure S5 and Supplementary Table S1). Moreover, the influence of $\mathrm{GdW}_{10}$ on the hemolytic behavior of red blood cells (RBCs) was also tested to further evaluate their biocompatibility. Negligible RBC hemolysis was detected, indicating that $\mathrm{GdW}_{10}$ possessed high blood compatibility (Supplementary Figure S6). Additionally, as shown in Supplementary Figure S7, no apparent tissue damage in the main organs was observed. These preliminary results showed that $\mathrm{GdW}_{10} @ \mathrm{BSA}$ exhibited good biocompatibility at the tested dosage in the short term.

\section{CONCLUSION}

In summary, we developed a new theranostic agent based on $\mathrm{GdW}_{10} @ B S A \mathrm{NCs}$ with an ultrasmall size and versatile properties. The as-prepared $\mathrm{GdW}_{10} @ \mathrm{BSA}$ NCs significantly enhanced CT/MR imaging signals and also elicited remarkable photothermal therapy (PTT)/radiotherapy therapy (RT) therapeutic effects. Moreover, H\&E staining, blood hematology, biochemistry analysis and hemolytic analysis revealed no noticeable $\mathrm{GdW}_{10} @ \mathrm{BSA} \mathrm{NCs}$ in vivo toxicity, indicating biocompatibility. Most importantly, because our work showed the potential for using $\mathrm{GdW}_{10} @ \mathrm{BSA}$ NCs as a small but powerful platform for multimodal image-guided PTT/RT therapy, other POM-based multifunctional nanotheranostics could be developed for cancer diagnoses and therapy. Because POMs have varying sizes, structures and compositions, there are a number of potential avenues for developing other nanomedicines with better therapeutic outcomes and fewer side effects.

\section{CONFLICT OF INTEREST}

The authors declare no conflict of interest.

\section{ACKNOWLEDGEMENTS}

This work was supported by the National Basic Research Programs of China (973 programs, Nos. 2012CB932500 and 2015CB932104) and the NSFC

(Nos. 21177128, 31751015, 21371173 and 21320102003).

1 Fernandez-Fernandez, A., Manchanda, R. \& McGoron, A. Theranostic applications of nanomaterials in cancer: drug delivery, image-guided therapy, and multifunctional platforms. Appl. Biochem. Biotech. 165, 1628-1651 (2011).

2 Song, J., Huang, P., Duan, H. \& Chen, X. Plasmonic vesicles of amphiphilic nanocrystals: optically active multifunctional platform for cancer diagnosis and therapy. Accounts Chem. Res. 48, 2506-2515 (2015).

3 Riehemann, K., Schneider, S., Luger, T., Godin, B., Ferrari, M. \& Fuchs, H. Nanomedicine-challenge and perspectives. Angew. Chem. Int. Ed. 48 872-897 (2009).

4 Rao, C., Matte, H. \& Maitra, U. Graphene analogues of inorganic layered materials. Angew. Chem. Int. Ed. 52, 13162-13185 (2013).

$5 \mathrm{Pu}$, K., Shuhendler, A., Jokerst, J., Mei, J., Gambhir, S., Bao, Z. \& Rao, J. Semiconducting polymer nanoparticles as photoacoustic molecular imaging probes in living mice. Nat. Nanotechnol. 9, 233-239 (2014).

6 Matte, H., Gomathi, A., Manna, A., Late, D., Datta, R., Pati, S. K. \& Rao, C. N. MoS and $\mathrm{WS}_{2}$ analogues of graphene. Angew. Chem. Int. Ed. 49, 4059-4062 (2010)

7 Lucky, S., Soo, K. \& Zhang, Y. Nanoparticles in photodynamic therapy. Chem. Rev. 115, 1990-2042 (2015)

8 Horcajada, P., Chalati, T., Serre, C., Gillet, B., Sebrie, C., Baati, T., Eubank, J. F., Heurtaux, D., Clayette, P., Kreuz, C., Chang, J. S., Hwang, Y. K., Marsaud, V., Bories, P. N., Cynober, L., Gil, S., Férey, G., Couvreur, P. \& Gref, R. Porous metal-organicframework nanoscale carriers as a potential platform for drug delivery and imaging. Nat. Mater. 9, 172-178 (2010).

9 Choi, H., Liu, W., Liu, F., Nasr, K., Misra, P., Bawendi, M. \& Frangioni, J. V. Design considerations for tumour-targeted nanoparticles. Nat. Nanotechnol. 5, 42-47 (2010).

10 Chen, Y., Tan, C., Zhang, H. \& Wang, L. Two-dimensional graphene analogues for biomedical applications. Chem. Soc. Rev. 44, 2681-2701 (2015).

11 Shao, K., Singha, S., Clemente-Casares, X., Tsai, S., Yang, Y. \& Santamaria, P. Nanoparticle-based immunotherapy for cancer. ACS Nano 9, 16-30 (2015).

12 Lammers, T., Kiessling, F., Hennink, W. \& Storm, G. Nanotheranostics and image-guided drug delivery: current concepts and future directions. Mol. Pharm. 7, 1899-1912 (2010).

13 Lammers, T., Aime, S., Wim, E., Storm, G. \& Kiessling, F. Theranostic nanomedicine. Accounts Chem. Res. 44, 1029-1038 (2011).

14 Xie, J., Lee, S. \& Chen, X. Nanoparticle-based theranostic agents. Adv. Drug Deliver. Rev. 62, 1064-1079 (2010)

15 Katz, E. \& Willner, I. Integrated nanoparticle-biomolecule hybrid systems: synthesis, properties, and applications. Angew. Chem. Int. Ed. 43, 6042-6108 (2004).

16 Janib, S., Moses, A. \& MacKay, J. Imaging and drug delivery using theranostic nanoparticles. Adv. Drug Deliver. Rev. 62, 1052-1063 (2010).

17 Xiao, Q., Zheng, X., Bu, W., Ge, W., Zhang, S., Chen, F., Xing, H., Ren, Q., Fan, W., Zhao, K., Hua, Y. \& Shi, J. A core/satellite multifunctional nanotheranostic for in vivo imaging and tumor eradication by radiation/photothermal synergistic therapy. J. Am. Chem. Soc. 135, 13041-13048 (2013).

18 Wang, Y., Wang, K., Zhao, J., Liu, X., Bu, J., Yan, X. \& Huang, R. Multifunctional mesoporous silica-coated graphene nanosheet used for chemo-photothermal synergistic targeted therapy of glioma. J. Am. Chem. Soc. 135, 4799-4804 (2013).

19 Wang, Y., Wang, H., Liu, D., Song, S., Wang, X. \& Zhang, H. Graphene oxide covalently grafted upconversion nanoparticles for combined NIR mediated imaging and photothermal/photodynamic cancer therapy. Biomaterials 34, 7715-7724 (2013).

20 Sahu, A., Choi, W., Lee, J. \& Tae, G. Graphene oxide mediated delivery of methylene blue for combined photodynamic and photothermal therapy. Biomaterials 34 , 6239-6248 (2013).

21 Barua, S. \& Mitragotri, S. Synergistic targeting of cell membrane, cytoplasm, and nucleus of cancer cells using rod-shaped nanoparticles. ACS Nano 7, 9558-9570 (2013).

22 Fan, Z., Dai, X., Lu, Y., Yu, E., Brahmbatt, N., Carter, N., Tchouwou, C., Singh, A. K., Jones, Y., Yu, H. \& Ray, P. C. Enhancing targeted tumor treatment by near IR 
light-activatable photodynamic-photothermal synergistic therapy. Mol. Pharm. 11, 1109-1116 (2014)

23 Tian, B., Wang, C., Zhang, S., Feng, L. \& Liu, Z. Photothermally enhanced photodynamic therapy delivered by nano-graphene oxide. ACS Nano $\mathbf{5}$, 7000-7009 (2011).

24 Bardhan, R., Lal, S., Joshi, A. \& Halas, A. Theranostic nanoshells from probe design to imaging and treatment of cancer. Accounts Chem. Res. 44, 936-946 (2011).

25 Melancon, M., Zhou, M. \& Li, C. Cancer theranostics with near-infrared light-activatable multimodal nanoparticles. Accounts Chem. Res. 44, 947-956 (2011).

26 Kelkar, S. \& Reineke, T. Theranostics: combining imaging and therapy. Bioconjugate Chem. 22, 1879-1903 (2011).

27 Huang, H., Barua, S., Sharma, G., Dey, S. \& Rege, K. Inorganic nanoparticles for cancer imaging and therapy. J. Control. Release 155, 344-357 (2011).

28 Choi, K., Liu, G., Lee, S. \& Chen, X. Theranostic nanoplatforms for simultaneous cancer imaging and therapy: current approaches and future perspectives. Nanoscale 4, 330-342 (2012)

29 Ahmed, N., Fessi, H. \& Elaissari, A. Theranostic applications of nanoparticles in cancer. Drug Discov. Today 17, 928-934 (2012).

30 Lux, F., Mignot, A., Mowat, P., Louis, C., Dufort, S., Bernhard, C., Denat, F., Boschetti, F., Brunet, C., Antoine, R., Dugourd, P., Laurent, S., Vander Elst, L., Muller, R., Sancey, L., Josserand, V., Coll, J. L., Stupar, V., Barbier, E., Rémy, C., Broisat, A., Ghezzi, C., Le Duc, G., Roux, S., Perriat, P. \& Tillement, O. Ultrasmall rigid particles as multimodal probes for medical applications. Angew. Chem. Int. Ed. 50, 12299-12303 (2011)

31 Chen, H., Wang, G., Tang, W., Todd, T., Zhen, Z., Tsang, C., Hekmatyar, K., Cowger, T., Hubbard, R. B., Zhang, W., Stickney, J., Shen, B. \& Xie, J. Gd-encapsulated carbonaceous dots with efficient renal clearance for magnetic resonance imaging. Adv. Mater. 26, 6761-6766 (2014).

32 Qi, W., Li, H. \& Wu, L. A novel, luminescent, silica-sol-gel hybrid based on surfactantencapsulated polyoxometalates. Adv. Mater. 19, 1983-1987 (2007).

33 Long, D., Tsunashima, R. \& Cronin, L. Polyoxometalates: building blocks for functional nanoscale systems. Angew. Chem. Int. Ed. 49, 1736-1758 (2010).

34 Rhule, J., Hill, C. \& Judd, D. Polyoxometalates in medicine. Chem. Rev. 98, 327-357 (1998)

35 Hussain, F., Conrad, F. \& Patzke, G. A Gadolinium-bridged polytungstoarsenate(III) nanocluster: $\left[\mathrm{Gd}_{8} \mathrm{As}_{12} \mathrm{~W}_{124} \mathrm{O}_{432}\left(\mathrm{H}_{2} \mathrm{O}\right)_{22}\right]^{60-}$. Angew. Chem. Int. Ed. 48, 9088-9091 (2009)

36 Kong, X., Ren, Y., Zheng, P., Long, Y., Long, L., Huang, R. \& Zheng, L. S. Construction of polyoxometalates-based coordination polymers through direct incorporation between polyoxometalates and the voids in a 2D network. Inorg. Chem. 45, 10702-10711 (2006)

37 Canny, J., Tere, Z., Thouvenot, R. \& Herve, G. Disubstituted tungstosilicates. 1. Synthesis, stability, and structure of the lacunary precursor polyanion $\gamma$-SiW $10 \mathrm{O}_{36}{ }^{8-}$. Inorg. Chem. 25, 2114-2119 (1986).

38 Fujita, Y., Ishihara, N., Fukaya, K., Srifa, A. \& Naruke, H. Fabrication of lanthanide decatungstate $\left[\mathrm{Ln}^{I I I / I V}\left(\mathrm{~W}_{5} \mathrm{O}_{18}\right)_{2}\right]^{8-/ 9-}\left(\mathrm{Ln}=\mathrm{Ce}^{\mathrm{IV} / I I I}, \mathrm{Eu}^{\mathrm{III}}\right.$, and $\left.\mathrm{Er}{ }^{\mathrm{III}}\right)$ thin films using spin-coating from aqueous solutions. J. Alloys Compd. 519, 136-139 (2012).

39 Bassil, B. \& Kortz, U. Divacant polyoxotungstates: reactivity of the gamma-decatungstates $\left[\gamma-\mathrm{XW}_{10} \mathrm{O}_{36}\right]^{8-}(\mathrm{X}=\mathrm{Si}, \mathrm{Ge})$. Dalton Trans. 40, 9649-9661 (2011).

40 Zheng, L., Gu, Z., Ma, Y., Zhang, G., Yao, J., Keita, B. \& Nadjo, L. Molecular interaction between europium decatungstate and histone $\mathrm{H} 1$ and its application as a novel biological labeling agent. J. Biol. Inorg. Chem. 15, 1079-1085 (2010).

41 Yang, H., Cheng, Y., Su, M., Xiao, Y., Hu, M., Wang, W. \& Wang, Q. Polyoxometalatebiomolecule conjugates: a new approach to create hybrid drugs for cancer therapeutics. Bioorg. Med. Chem. Lett. 23, 1462-1466 (2013).

42 Yamase, T. Anti-tumor-viral, and -bacterial activities of polyoxometalates for realizing an inorganic drug. J. Mater. Chem. 15, 4773-4782 (2005).

43 Wang, X., Liu, J., Li, J., Yang, Y., Liu, J., Li, B. \& Pope, M. T. Synthesis and antitumor activity of cyclopentadienyltitanium substituted polyoxotungstate $\left[\mathrm{CoW}_{11} \mathrm{O}_{39}(\mathrm{CpTi})\right]^{7-}$ $\left(\mathrm{Cp}=\eta^{5}-\mathrm{C}_{5} \mathrm{H}_{5}\right)$. J. Inorg. Biochem. 94, 279-284 (2003).

44 Wang, X., Li, F., Liu, S. \& Pope, M. New liposome-encapsulated-polyoxometalates: synthesis and antitumoral activity. J. Inorg. Biochem. 99, 452-457 (2005).

45 Ogata, A., Yanagie, H., Ishikawa, E., Morishita, Y., Mitsui, S., Yamashita, A., Hasumi, K., Takamoto, S., Yamase, T. \& Eriguchi, M. Antitumour effect of polyoxomolybdates: induction of apoptotic cell death and autophagy in vitro and in vivo models. Brit. Cancer 98, 399-409 (2008).

46 Ogata, A., Mitsui, S., Yanagie, H., Kasano, H., Hisa, T., Yamase, T. \& Eriguchi, M. A novel anti-tumor agent, polyoxomolybdate induces apoptotic cell death in AsPC-1 human pancreatic cancer cells. Biomed. Pharmacother. 59, 240-244 (2005).

47 Menon, D., Thomas, R., Narayanan, S., Maya, S., Jayakumar, R., Hussain, F., Lakshmanan, V. \& Nair, S. A novel chitosan/polyoxometalate nano-complex for anticancer applications. Carbohyd. Polym. 84, 887-893 (2011)

48 Geng, J., Li, M., Ren, J., Wang, E. \& Qu, X. Polyoxometalates as inhibitors of the aggregation of amyloid $\beta$ peptides associated with Alzheimer's disease. Angew. Chem. Int. Ed. 123, 4270-4274 (2011).

49 Gao, N., Sun, H., Dong, K., Ren, J., Duan, T., Xu, C. \& Qu, X. Transition-metalsubstituted polyoxometalate derivatives as functional anti-amyloid agents for Alzheimer's disease. Nat. Commun. 5, 3422 (2014).

50 Zheng, L., Ma, Y., Zhang, G., Yao, J., Keita, B. \& Nadjo, L. A multitechnique study of europium decatungstate and human serum albumin molecular interaction. Phys. Chem. Chem. Phys. 12, 1299-1304 (2010).
51 Zhang, Y., Bo, X., Nsabimana, A., Munyentwali, A., Han, C., Li, M. \& Guo, L. Green and facile synthesis of an Au nanoparticles@polyoxometalate/ordered mesoporous carbon tri-component nanocomposite and its electrochemical applications. Biosens. Bioelectron. 66, 191-197 (2015).

52 Stefan, L. \& But, S. A new spectrophotometric method for the determination and simultaneous determination of tungsten and molybdenum in polyoxometalates and their Ln(III) complexes. J. Alloys Compd. 303-304, 132-136 (2000).

$53 \mathrm{Lis}, \mathrm{S}$. \& But, S. Spectroscopic studies of $\mathrm{Eu}(\mathrm{III})$ and $\mathrm{Nd}(\mathrm{III})$ complexes with several polyoxometalates. J. Alloys Compd. 300-301, 370-376 (2000).

54 Lubal, P., Koprivova, H., Sedo, O., Havel, J., Lis, S. \& But, S. Simultaneous determination of molybdenum(VI) and tungsten $(\mathrm{VI})$ and its application in elemental analysis of polyoxometalates. Talanta 69, 800-806 (2006).

55 AIDamen, M., Clemente-Juan, J., Coronado, E., Martı'-Gastaldo, C. \& Gaita-Ariño, A. Mononuclear lanthanide single-molecule magnets based on polyoxometalates. J. Am. Chem. Soc. 130, 8874-8875 (2008).

56 Clemente-León, M., Coronado, E., Delhaes, P., Gómez-García, C. \& Mingotaud, C. Hybrid Langmuir-Blodgett films formed by alternating layers of magnetic polyoxometalate clusters and organic donor molecules-towards the preparation of multifunctional molecular materials. Adv. Mater. 13, 574-577 (2001).

57 Martinez-Perez, M., Montero, O., Evangelisti, M., Luis, F., Sese, J., Cardona-Serra, S. \& Coronado, E. Fragmenting gadolinium: mononuclear polyoxometalate-based magnetic coolers for ultra-low temperatures. Adv. Mater. 24, 4301-4305 (2012)

58 Martínez-Pérez, M., Cardona-Serra, S., Schlegel, C., Moro, F., Alonso, P., Prima-García, H., Clemente-Juan, J. M., Evangelisti, M., Gaita-Ariño, A., Sesé, J., van Slageren, J., Coronado, E. \& Luis, F. Gd-based single-ion magnets with tunable magnetic anisotropy: molecular design of spin qubits. Phys. Rev. Lett. 108, 247213-247218 (2012)

59 Cardona-Serra, S., Clemente-Juan, J., Coronado, E., Gaita-Arino, A., Camon, A., Evangelisti, M., Luis, F., Martínez-Pérez, M. J. \& Sesé, J. Lanthanoid single-ion magnets based on polyoxometalates with a 5-fold symmetry: the series $\left[\mathrm{LnP}_{5} \mathrm{~W}_{30} \mathrm{O}_{110}\right]$ 12- $\left(\mathrm{Ln}^{3+}=\mathrm{Tb}\right.$, Dy, Ho, Er, Tm, and Yb). J. Am. Chem. Soc. 134, 14982-14990 (2012).

60 Müller, A., Peters, F., Pope, M. \& Gatteschi, D. Polyoxometalates very large clustersnanoscale magnets. Chem. Rev. 98, 239-271 (1998).

61 Schaming, D., Farha, R., Xu, H., Goldmann, M. \& Ruhlmann, L. Formation and photocatalytic properties of nanocomposite films containing both tetracobalt dawson-derived sandwich polyanions and tetracationic porphyrins. Langmuir 27. 132-143 (2011)

62 Dolbecq, A., Mialane, P., Keita, B. \& Nadjo, L. Polyoxometalate-based materials for efficient solar and visible light harvesting: application to the photocatalytic degradation of azo dyes. J. Mater. Chem. 22, 24509-24521 (2012).

63 Nisar, A., Zhuang, J. \& Wang, X. Construction of amphiphilic polyoxometalate mesostructures as a highly efficient desulfurization catalyst. Adv. Mater. 23, 1130-1135 (2011).

$64 \mathrm{Ni}$, L., Patscheider, J., Baldridge, K. \& Patzke, G. New perspectives on polyoxometalate catalysts: alcohol oxidation with $\mathrm{Zn} / \mathrm{Sb}$-polyoxotungstates. Chem-Eur. J. 18 , 13293-13298 (2012).

65 Liu, R., Li, S., Yu, X., Zhang, G., Zhang, S., Yao, J. \& Zhi, L. A general green strategy for fabricating metal nanoparticles/polyoxometalate/graphene tri-component nanohybrids: enhanced electrocatalytic properties. J. Mater. Chem. 22, 3319-3322 (2012).

$66 \mathrm{Ju}$, F., VanderVelde, D. \& Nikolla, E. Molybdenum-based polyoxometalates as highly active and selective catalysts for the epimerization of aldoses. ACS Catal. 4, 1358-1364 (2014)

67 Carraro, M., Fiorani, G., Mognon, L., Caneva, F., Gardan, M., Maccato, C. \& Bonchio, M. Hybrid polyoxotungstates as functional comonomers in new crosslinked catalytic polymers for sustainable oxidation with hydrogen peroxide. Chem-Eur. J. 18, 13195-13202 (2012).

68 Liu, Y., Shi, D., Zhao, J., Wang, X., Cheng, H., Chen, L., Ma, P. \& Niu, J. A novel 2D organic-inorganic hybrid $3 \mathrm{~d}-4 \mathrm{f}$ polyoxometalate built by $\left[\mathrm{Gd}\left(\alpha-\mathrm{PW}_{11} \mathrm{O}_{39}\right)_{2}\right]^{11-}$ units and $\left[\mathrm{Cu}(\mathrm{Dap})_{2}\right]^{2+}$ bridges. Russ. J. Coord. Chem. 37, 712-717 (2011).

69 Chai, W., Wang, S., Zhao, H., Liu, G., Fischer, K., Li, H., Wu, L. \& Schmidt, M. Hybrid assemblies based on a gadolinium-containing polyoxometalate and a cationic polymer with spermine side chains for enhanced MRI contrast agents. Chem-Eur. J. 19, 13317-13321 (2013).

70 Cao, J., Liu, S., Cao, R., Xie, L., Ren, Y., Gao, C. \& Xu, L. Organic-inorganic hybrids assembled by bis(undecatungstophosphate) lanthanates and dinuclear copper (ii)-oxalate complexes. Dalton Trans. 115-120 (2008)

71 Sun, G., Feng, J., Wu, H., Pei, F., Fang, K. \& Lei, H. Investigation of sandwiched gadolinium (III) complexes with tungstosilicates as potential MRI contrast agents. Magn. Reson. Imaging 22, 421-426 (2004)

$72 \mathrm{Li}$, Z., Li, W., Li, X., Pei, F., Li, Y. \& Lei, H. The gadolinium complexes with polyoxometalates as potential mri contrast agents. Magn. Reson. Imaging 25, 412-417 (2007).

73 Da-liang, K., Bo, W., Sheng-yan, Z., Hai-shan, Y. \& Yang, J. Volume-related efficiency of gadolinium polyoxometalates as MRI contrast agents. Chem. Res. Chin. Univ. 29, 1055-1058 (2013).

74 Feng, J., Li, X., Pei, F., Sun, G., Zhang, X. \& Liu, M. An evaluation of gadolinium polyoxometalates as possible MRI contrast agent. Magn. Reson. Imaging 20, 407-412 (2002) 
75 Feng, J., Sun, G., Pei, F. \& Liu, M. Comparison between GdDTPA and two gadolinium polyoxometalates as potential MRI contrast agents. J. Inorg. Biochem. 92 193-199 (2002).

76 Lux, F., Sancey, L., Bianchi, A., Crémillieux, Y., Roux, S. \& Tillement, O. Gadoliniumbased nanoparticles for theranostic MRI-radiosensitization. Nanomedicine 10, 1801-1815 (2015).

77 Kim, D., Seog, J., Kim, M., Yang, M., Gillette, E., Lee, S. \& Han, S. W. Polyoxometalate-mediated one-pot synthesis of Pd nanocrystals with controlled morphologies for efficient chemical and electrochemical catalysis. Chem-Eur. J. 21, 5387-5394 (2015).

78 AIDamen, M., Cardona-Serra, S., Clemente-Juan, J., Coronado, E., Gaita-Ariño, E., Martí-Gastaldo, C., Luis, F. \& Montero, O. Mononuclear lanthanide single molecule magnets based on the polyoxometalates $\left[\mathrm{Ln}\left(\mathrm{W}_{5} \mathrm{O}_{18}\right)_{2}\right]^{9-}$ and $\left[\mathrm{Ln}\left(2-\mathrm{SiW}_{11} \mathrm{O}_{39}\right)_{2}\right]^{13}-(\mathrm{LnIII}) \mathrm{Tb}, \mathrm{Dy}, \mathrm{Ho}, \mathrm{Er}, \mathrm{Tm}$, and Yb. Inorg. Chem. 48, 3467-3479 (2009).

79 Goovaerts, V., Stroobants, K., Absillis, G. \& Parac-Vogt, T. Molecular interactions between serum albumin proteins and Keggin type polyoxometalates studied using luminescence spectroscopy. Phys. Chem. Chem. Phys. 15, 18378-18387 (2013).

80 Hungerford, G., Suhling, K. \& Green, M. Luminescence enhancement of a europium containing polyoxometalate on interaction with bovine serum albumin. Photochem. Photobiol. Sci. 7, 734-737 (2008).

81 Gao, P., Zhang, S., Li, H., Zhang, T., Wu, Y. \& Wu, L. A two-step binding process of Eu-containing polyoxometalates to bovine serum albumin. Langmuir 31, 10888-10896 (2015).
82 Zhou, Z., Kong, B., Yu, C., Shi, X., Wang, M., Liu, W., Sun, Y., Zhang, Y., Yang, H. \& Yang, S. Tungsten oxide nanorods: an efficient nanoplatform for tumor CT imaging and photothermal therapy. Sci. Rep. 4, 3653 (2014).

83 Lee, N., Choi, S. \& Hyeon, T. Nano-Sized CT Contrast agents. Adv. Mater. 25, 2641-2660 (2013).

84 Shigeta, S., Mori, S., Watanabe, J., Soeda, S., Takahashi, K. \& Yamase, T. Synergistic anti-influenza virus A (H1N1) activities of PM-523 (polyoxometalate) and ribavirin in vitro and in vivo. Antimicrob. Agents. Chemother. 41, 1423-1427 (1997).

85 Shigeta, S., Watanabe, J., Baba, M., Khenkin, A., Hill, C. \& Schinazi, R. In vitro antimyxovirus and anti-human immunodeficiency virus activities of polyoxometalates. Antivir. Chem. Chemother. 6, 114-122 (1995).

(c) (i) This work is licensed under a Creative Commons Attribution 4.0 International License. The images or other third party material in this article are included in the article's Creative Commons license, unless indicated otherwise in the credit line; if the material is not included under the Creative Commons license, users will need to obtain permission from the license holder to reproduce the material. To view a copy of this license, visit http:// creativecommons.org/licenses/by/4.0/

Supplementary Information accompanies the paper on the NPG Asia Materials website (http://www.nature.com/am) 